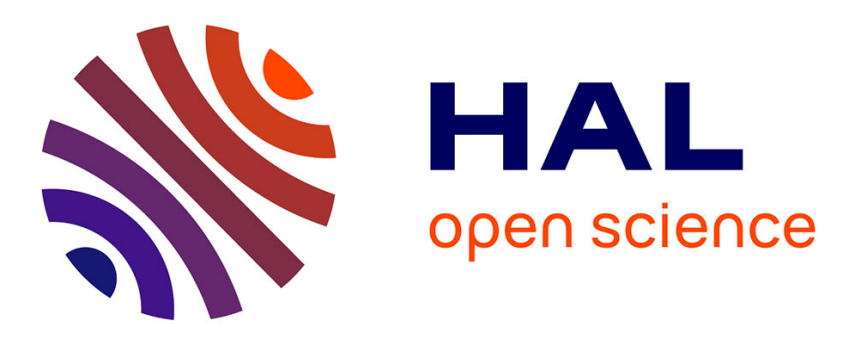

\title{
Estimation of rain kinetic energy from radar reflectivity and/or rain rate based on a scaling formulation of the raindrop size distribution
}

\author{
Nan Yu, Brice Boudevillain, Guy Delrieu, Remko Uijlenhoet
}

\section{- To cite this version:}

Nan Yu, Brice Boudevillain, Guy Delrieu, Remko Uijlenhoet. Estimation of rain kinetic energy from radar reflectivity and/or rain rate based on a scaling formulation of the raindrop size distribution. Water Resources Research, 2012, 48 (4), pp.1645 - 1663. 10.1029/2011WR011437 . hal-01897126

\author{
HAL Id: hal-01897126 \\ https://hal.science/hal-01897126
}

Submitted on 4 Nov 2021

HAL is a multi-disciplinary open access archive for the deposit and dissemination of scientific research documents, whether they are published or not. The documents may come from teaching and research institutions in France or abroad, or from public or private research centers.
L'archive ouverte pluridisciplinaire HAL, est destinée au dépôt et à la diffusion de documents scientifiques de niveau recherche, publiés ou non, émanant des établissements d'enseignement et de recherche français ou étrangers, des laboratoires publics ou privés. 


\title{
Estimation of rain kinetic energy from radar reflectivity and/or rain rate based on a scaling formulation of the raindrop size distribution
}

\author{
Nan Yu, ${ }^{1}$ Brice Boudevillain, ${ }^{1}$ Guy Delrieu, ${ }^{1}$ and Remko Uijlenhoet ${ }^{2}$ \\ Received 23 September 2011; revised 10 February 2012; accepted 15 February 2012; published 28 April 2012.
}

[1] This study offers an approach to estimate the rainfall kinetic energy (KE) by rain intensity $(R)$ and radar reflectivity factor $(Z)$ separately or jointly on the basis of a one- or two-moment scaled raindrop size distribution (DSD) formulation, which contains (1) $R$ and/or $Z$ observations and (2) the dimensionless probability density function (pdf) of a scaled raindrop diameter. The key point is to explain all variability of the DSD by the evolution of the explaining moments $(R$ and $Z)$; hence the pdf is considered as constant. A robust method is proposed to estimate the climatological values of the parameters with a 28 month DSD data set collected in the Cévennes-Vivarais region of France. Three relationships (KE- $R, \mathrm{KE}-Z$, and KE- $R Z$ ), which link the observations ( $R$ and/or $Z$ ) to rainfall kinetic energy (KE), are established. As expected, the assessment using the disdrometer data indicates that (1) because of the proximity of the moment orders, the KE- $Z$ relationship exhibits less variability than the KE- $R$ relationship and (2) the combination of $R$ and $Z$ yields a significant improvement of the estimation of $\mathrm{KE}$ compared to the single-moment formulations. Subsequently, a first attempt to spatialize the kinetic energy using radar and rain gauge measurements is presented for a convective event, showing a promising potential for erosion process studies. Different from the application with the disdrometer data, the performance of the KE- $Z$ relationship degrades compared to the KE- $R$ relationship as a result of a bias and/or the sampling characteristics of the radar data.

Citation: Yu, N., B. Boudevillain, G. Delrieu, and R. Uijlenhoet (2012), Estimation of rain kinetic energy from radar reflectivity and/or rain rate based on a scaling formulation of the raindrop size distribution, Water Resour. Res., 48, W04505, doi:10.1029/2011WR011437.

\section{Introduction}

[2] Soil erosion due to rain is a major issue in the fields of agriculture, environment, and water management. All studies on soil erosion have suggested that increased rainfall amounts and intensities lead to greater rates of erosion [e.g., Intergovernmental Panel on Climate Change, 2007]. In particular, rainfall kinetic energy has often been suggested as an indicator of rainfall erosivity [Fornis et al., 2005]. Over the past decades, many erosion models have been developed, such as the Water Erosion Prediction Project model (WEPP) [Laflen et al., 1997] and the European Soil Erosion Model (EUROSEM) [Morgan et al., 1998]. These models require rainfall time series with moderate to high temporal and spatial resolution [Van Dijk et al., 2005], which is a restriction due to the large rain variability and the limitation of rain gauge observations. The most common approach to estimate rainfall kinetic energy is by means of an empirical relationship between the kinetic energy flux density KE and rain intensity $R[$ Mihara, 1951; Kinnell, 1973; Sempere Torres et al., 1992]. Various mathematical expressions and parameterizations for the KE- $R$

\footnotetext{
${ }^{1}$ LTHE, UMR 5564, UJF-Grenoble 1/CNRS/G-INP/IRD, Grenoble, France.

${ }^{2}$ Hydrology and Quantitative Water Management Group, Wageningen University, Wageningen, Netherlands.
}

Copyright 2012 by the American Geophysical Union 0043-1397/12/2011WR011437 relationship have been presented in the literature. In order to study the physical interpretation behind different KE- $R$ relationships, several mathematical distributions have been introduced to account for the variation in raindrop size distribution (DSD). Uijlenhoet and Stricker [1999] developed an approach to link KE to $R$ on the basis of the exponential DSD. Later, Salles et al. [2002] proposed a KE- $R$ relationship according to the one-moment scaling formulation of the DSD. Their work suggested that the varying character of the DSD, which depends on the type of rain (convective or stratiform) and the geographical location, are the main factors explaining the variability of KE- $R$ relationships. Fox [2004] investigated theoretical KE- $R$ relationships on the basis of the gamma distribution [Ulbrich, 1983] and pointed out that the KE- $R$ relationship is poorly defined unless some assumptions about the parameters of the gamma distribution are made. He also found that the assumption of an exponential DSD leads to an overestimation of the kinetic energy flux density. Assuming that the DSD is determined mainly by the breakup process rather than the initial DSD [Assouline and Mualem, 1989], Mualem and Assouline [1986] proposed a Weibull distribution with two parameters to derive the KE- $R$ relationship. This approach showed advantages in KE estimation for light rainfall. Additionally, to overcome the limitation of a rain gauge observation network, Steiner and Smith [2000] showed the potential advantage of radar reflectivity factor $(Z)$ for estimating $\mathrm{KE}$, which can provide detailed spatial and temporal information about rain storms. 
[3] The first purpose of this paper is to investigate the $\mathrm{KE}-R$, KE- $Z$, and the KE- $R Z$ relationships using onemoment [Sempere Torres et al., 1994] and two-moment normalizations of the DSD following a number of previous contributions regarding a revised mathematical formulation of the DSD [Testud et al., 2001; Illingworth and Blackman, 2002; Lee et al., 2004; N. Yu et al., Unified formulation of single and multi-moment normalizations of the raindrop size distribution based on the gamma probability density function, submitted to Journal of Applied Meteorology and Climatology, 2012, hereinafter referred to as Yu et al., submitted manuscript, 2012]. It is hoped that the radar reflectivity factor $(Z)$ in combination with the rain rate $(R)$ can improve the estimation of rainfall kinetic energy flux density. The study is organized as follows: section 2 gives a brief description of the observed data used in this study. Section 3 outlines the general DSD scaling formulations on the basis of the concept of the probability density function (pdf) of a scaled raindrop diameter. Section 4 explores a robust method to estimate the climatic values of the DSD parameters in the one- and two-moment formulations. Three relationships to estimate the rainfall kinetic energy flux density (KE- $R$, KE- $Z$, and KE- $R Z$ ) are derived using a 28 month DSD data set collected in the Cévennes-Vivarais region, France, which is a region prone to heavy precipitation events and subsequent flash floods [Delrieu et al., 2005]. Finally, we select, in section 5, one particular rain event to start addressing the second objective of the article, which is to study how rain gauge and radar measurements could be used separately and/or in conjunction to spatialize the kinetic energy flux over a region of interest.

\section{Context and Data Set}

[4] The Cévennes-Vivarais region, which is located in the southeast of France, is a key focus area of our study.
The transfer of heat and moisture from the Mediterranean Sea colliding with northern cold air creates favorable conditions for flooding in autumn [Nuissier et al., 2008]. The orographic features of this region tend to enhance the rainfall by providing additional lift of air mass [Anquetin et al., 2003]. In order to study the water cycle in the Mediterranean, with particular interest in hydrometeorological extreme events, the activities of the Cévennes-Vivarais Mediterranean Hydro-meteorological Observatory [Delrieu et al., 2005; Boudevillain et al., 2011] have been carried out since 2000. The observation data for the current study include rain gauge and laser optical disdrometer records, together with the measurements of an $\mathrm{S}$ band radar installed near Nîmes (Figure 1). The OTT Parsivel optical disdrometer was installed at Alès in 2004 and measures raindrop size distributions (DSDs) at $10 \mathrm{~s}$ intervals. Next to the disdrometer (at about $2 \mathrm{~m}$ distance), a tipping bucket rain gauge was set up to check the disdrometer measurements. About 49 kilometers away to the southeast of Alès, the Nîmes S band radar of Météo France surveys the precipitation systems with a volume scan time of $5 \mathrm{~min}$. For the purpose of this study, we have selected a 28 month disdrometer and rain gauge data set from September 2006 to December 2008 as a climatic database; both the DSD and rain gauge data were integrated over $5 \mathrm{~min}$ intervals to coincide with the radar observations. The disdrometer data were filtered on the basis of the theoretical relationship between measured fall velocity and the diameter of raindrops with a tolerance of $60 \%$ [Jaffrain and Berne, 2011]. All 5 min DSD spectra with rain intensities less than $0.5 \mathrm{~mm} \mathrm{~h}^{-1}$ were removed from the sample. A $14 \mathrm{~h}$ intense rain event which contains different types of rainfall has been removed from the data set in order to validate the KE estimation models in section 4.3. We show this event in Figure 2 to illustrate the comparison of the rain intensity

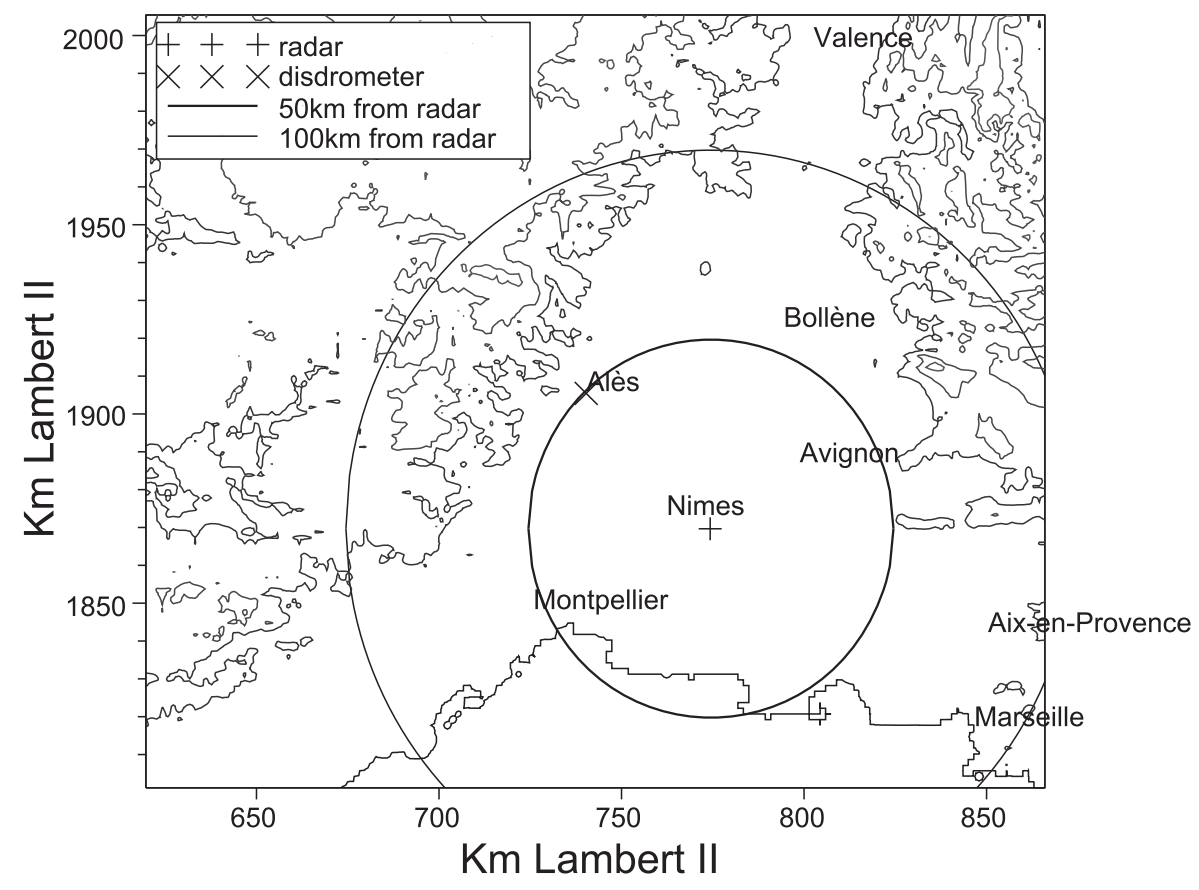

Figure 1. Topographic map of the Cévennes-Vivarais region in southern France with the locations of the disdrometer and the Nîmes radar. 
$a$
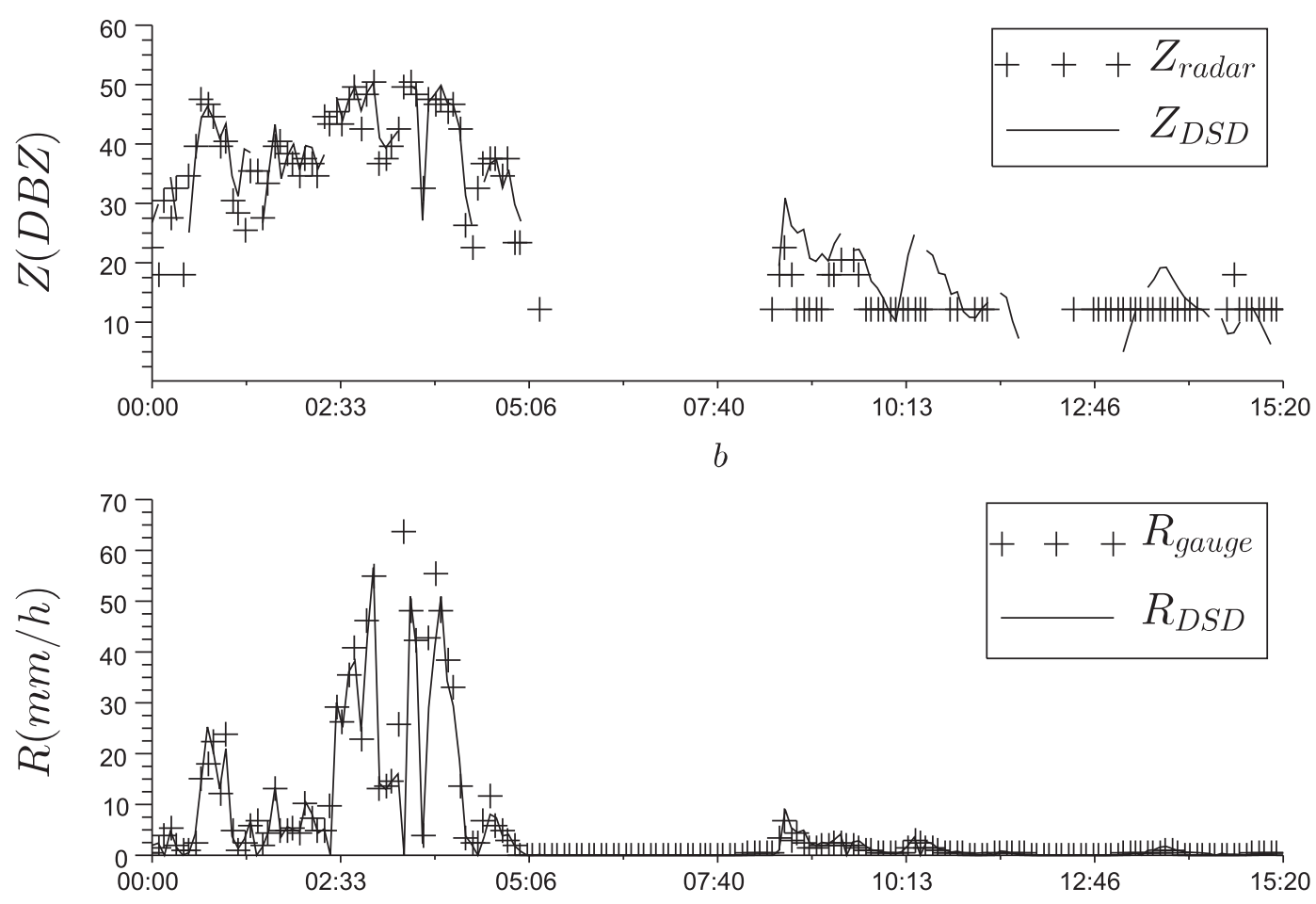

Figure 2. Comparison of (a) reflectivity factor measured by disdrometer and weather radar and (b) rain intensity recorded by disdrometer and rain gauge for the heavy rainfall event of 22 October 2008.

$\left(R_{d s d}\right)$ derived from the DSD spectra and recorded by the rain gauge $\left(R_{g}\right)$, as well as the reflectivity derived from the DSD spectra $\left(Z_{d s d}\right)$ and measured by the Nîmes radar $\left(Z_{r}\right)$ at the $0.6^{\circ}$ elevation angle, corresponding to a resolution volume of approximately $1 \mathrm{~km}^{3}$ above Alès. The accumulated rainfall measured by the rain gauge is $77.0 \mathrm{~mm}$, compared to the $75.5 \mathrm{~mm}$ measured by the Parsivel. The comparison confirms that a good agreement exists among the three measuring devices regardless of the different sampling characteristics.

\section{DSD Scaling Formulation and Relationships Between Moments}

[5] In the beginning of section 3 , the definition of the rainfall kinetic energy flux density (KE) is clarified. Next, considering the probability density function (pdf) of a scaled diameter $D / D_{c}$, a two-parameter gamma function is introduced to model the DSD as a function of the liquid water content (LWC) and a characteristic diameter $\left(D_{c}\right)$. Assuming power law relationships between the scaling variables (LWC and $D_{c}$ ) and available observations ( $R$ and/ or $Z$ ), one- and two-moment DSD formulations are thus proposed.

\subsection{Definition of the Rainfall Kinetic Energy Flux Density}

[6] There are two raindrop kinetic energy variables proposed in the literature. One is the kinetic energy flux density per unit area per unit time, denoted KE hereafter, with units of $\mathrm{J} \mathrm{m}^{-2} \mathrm{~h}^{-1}$, which expresses the rainfall energy on a unit surface during a unit time; the other is the kinetic energy flux density per unit area per unit depth (denoted $\mathrm{KE}_{\mathrm{mm}}$ hereafter, with units of $\mathrm{J} \mathrm{m}^{-2} \mathrm{~mm}^{-1}$ ), which is defined as the ratio between $\mathrm{KE}$ and the rain rate $R$. Although the latter is most widely used in soil erosion studies, Salles et al. [2002] suggested that, both from a theoretical and a practical point of view, the KE- $R$ relationship should be used instead of the $\mathrm{KE}_{\mathrm{mm}}-R$ relationship. They explained the preference for $\mathrm{KE}_{\mathrm{mm}}$ in past studies by the nonautomatic DSD observation techniques. Following Salles et al. [2002], we express the kinetic energy flux density per unit area per unit time $\left(\mathrm{KE}, \mathrm{J} \mathrm{m}^{-2} \mathrm{~h}^{-1}\right)$ as

$$
\mathrm{KE}=3 \times 10^{-7} \rho \pi \sum_{i} X\left(D_{i}\right) D_{i}^{3} v_{t}^{2}\left(D_{i}\right)
$$

where $\rho$ is the water density $\left(\mathrm{kg} \mathrm{m}^{-3}\right)$ in standard conditions; $X\left(D_{i}\right)$ (drops $\left.\mathrm{m}^{-2} \mathrm{~s}^{-1}\right)$ is the number of raindrops of diameter $D_{i}(\mathrm{~mm})$ falling on a unit surface $\left(1 \mathrm{~m}^{2}\right)$ during a unit time interval $(1 \mathrm{~s})$ and $v_{t}\left(D_{i}\right)\left(\mathrm{m} \mathrm{s}^{-1}\right)$ is the terminal velocity of a raindrop of diameter $D_{i}$. Converting the raindrop flux $X(D)$ into the raindrop concentration in a unit volume $N(D) d D\left(\mathrm{~m}^{-3}\right.$, with $N(D)$ in $\mathrm{mm}^{-1} \mathrm{~m}^{-3}$ and $d D$ in $\left.\mathrm{mm}\right)$ through

$$
X(D)=N(D) v_{t}(D) d D
$$

and integrating over the raindrop diameter range yields

$$
\mathrm{KE}=3 \times 10^{-7} \rho \pi \int_{0}^{\infty} N(D) D^{3} v_{t}^{3}(D) d D .
$$


[7] The raindrop fall velocity $\left(v_{t}\right)$ plays an important role in determining the disdrometer resolution volumes and the conversion of the rainfall flux variables (such as the $R, \mathrm{KE}$ ) into the state variables (such as the $N(D), Z$ ) [Salles and Creutin, 2003]. It is generally assumed that the raindrops have reached their terminal velocities when they hit the ground. Previous theoretical and experimental studies showed that the terminal velocity can be expressed as a function of the drop diameter. Power law and exponential models have been proposed to represent physically based $v_{t}(D)$ models [e.g., Beard, 1976] or data-fitted models [Gunn and Kinzer, 1949; Best, 1950; Atlas and Ulbrich, 1977; Gossard et al., 1992]. In addition, Erpul et al. [2003] showed that the vertical wind speed has significant effects on the raindrop velocity (updrafts, downdrafts). This would be a motivation for using measured velocities instead of a velocity model depending on the diameter. However, several authors [Tokay et al., 2003; Jaffrain and Berne, 2011] claimed that the Parsivel velocity measurements are not accurate enough; their results are consistent with our observations. We will have the opportunity in the near future to compare the velocity measurements of the Parsivel with those of a 2DVD. In the present study, we therefore use the well-known power law model proposed by Atlas and Ulbrich [1977], which has already been considered in many previous studies because of its convenient mathematical formulation:

$$
v_{t}(D)=3.78 D^{0.67}
$$

With the above mentioned units, replacing the velocity in (3) by the expression (4) yields a final formulation for the kinetic energy flux density

$$
\mathrm{KE}=5.09 \times 10^{-2} \int_{0}^{\infty} N(D) D^{5.01} d D,
$$

which indicates $\mathrm{KE}$ is roughly proportional to the fifthorder moment of the DSD. Let us recall that, with the same hypothesis regarding the terminal velocity, the rain rate $\left(\mathrm{mm} \mathrm{h}^{-1}\right)$ and the radar reflectivity factor $\left(\mathrm{mm}^{6} \mathrm{~m}^{-3}\right)$ are expressed as

$$
R=6.92 \times 10^{-3} \int_{0}^{\infty} N(D) D^{3.67} d D
$$

and

$$
Z=\int_{0}^{\infty} N(D) D^{6} d D
$$

respectively. Equations (6) and (7) clearly show the potential of the rain rate, proportional to the 3.67 th-order moment of the DSD, and the radar reflectivity factor, equal to the sixth-order moment, for estimating the rain kinetic energy flux density, separately or in conjunction.

\subsection{DSD Scaling Formulation as a Function of Disdrometer Measurables}

[8] As pointed out by Porrà et al. [1998] and Sempere Torres et al. [1998], the raindrop size distribution is in fact a mixture of two different notions, namely that of the number concentration $N_{t}\left(\mathrm{~m}^{-3}\right)$ of raindrops within a unit air volume and that of a dimensionless probability density function (pdf) $g(x)$ (dimensionless) of the scaled raindrop diameter $x$ (dimensionless) as follows:

$$
N(D)=\frac{N_{t}}{D_{c}} g(x), \quad x=\frac{D}{D_{c}},
$$

where $D_{c}(\mathrm{~mm})$ is a characteristic raindrop diameter. Following Testud et al. [2001] and motivated by the classical observation problems of small rain droplets as well as our interest in high-order moments of the DSD (see equations (5)-(7)), we have chosen as the characteristic diameter the ratio of the fourth- to the third-order moments hereafter:

$$
D_{c}=M_{4} / M_{3}
$$

As previously proposed by Lee et al. [2004] and Yu et al. (submitted manuscript, 2012), a two-parameter gamma function is selected to model the probability density function (pdf) of raindrop sizes:

$$
g(x ; \lambda, \mu)=\frac{\lambda^{\mu+1}}{\Gamma(\mu+1)} x^{\mu} \exp (-\lambda x) .
$$

Introducing the pdf model (10) into (8) yields

$$
N(D)=\frac{N_{t}}{D_{c}}\left[\frac{\lambda^{\mu+1}}{\Gamma(\mu+1)}\left(\frac{D}{D_{c}}\right)^{\mu} \exp \left(-\lambda \frac{D}{D_{c}}\right)\right] .
$$

Using (11), any DSD moment of order $k$ can be expressed as

$$
M_{k}=\frac{\Gamma(\mu+k+1)}{\Gamma(\mu+1)} \frac{N_{t} D_{c}^{k}}{\lambda^{k}} .
$$

We substitute the number concentration $N_{t}$, which is hardly measurable in practice, especially regarding the smallest rain droplets, by the liquid water content per unit air volume (LWC, $\mathrm{kg} \mathrm{m}^{-3}$ ):

$$
\mathrm{LWC}=\frac{\pi \rho}{6} M_{3}=\frac{\pi \rho}{6} \frac{\Gamma(\mu+4)}{\Gamma(\mu+1)} \frac{N_{t} D_{c}^{3}}{\lambda^{3}} .
$$

Substituting (13) into (11) yields

$$
N(D)=\left[C_{L W C} \frac{\mathrm{LWC}}{D_{c}^{4}}\right]\left[\frac{\lambda^{\mu+1}}{\Gamma(\mu+1)}\left(\frac{D}{D_{c}}\right)^{\mu} \exp \left(-\frac{\lambda D}{D_{c}}\right)\right],
$$

with

$$
C_{L W C}=\frac{6}{\pi \rho} \frac{\Gamma(\mu+1) \lambda^{3}}{\Gamma(\mu+4)} .
$$

Equation (14) could be further simplified, however we choose not to mix the two terms between square brackets in order to keep the expression for $g(x)$ (the second term on the right hand side of (14)) apparent. Although more complex than classical DSD models (exponential, gamma) and less general than (8), the DSD formulation (14) has several definite advantages since (1) a clear definition of the 
statistical distribution of the raindrop diameter is used with the dimensionless pdf of the scaled diameter $g(x)$ (note in particular that $\left.\int_{0}^{\infty} g(x) d x=1\right)$, (2) the two parameters $\lambda$ and $\mu$ are dimensionless and are probably related to the type of rainfall (stratiform, convective, and orographic), and (3) besides the diameter $D$ and the two parameters, the DSD depends on two physical variables, namely, the liquid water content LWC and the characteristic diameter $D_{c}$, which are related to the third- and fourth-order moments of the DSD. These two moments are better measured by the Parsivel compared to $N_{t}$, which is significantly influenced by the measurement error of small raindrops.

\subsection{DSD Scaling Formulation as a Function of One or Two DSD Moments Accessible From Other Measurement Techniques}

[9] To extend the application of the DSD model to DSD moments accessible by measurement techniques other than disdrometers (e.g., rain rate from rain gauges and reflectivity factor from weather radar systems), power law relationships can be used to relate the scaling moments (LWC and $D_{c}$ ) of (14) to these other moments ( $R$ and/or $Z$ ). In the case one moment (denoted $M_{i}$ hereafter) is available, we consider simple power law models :

$$
\begin{gathered}
\mathrm{LWC}=C_{i} M_{i}^{\alpha_{i}} \\
D_{c}=K_{i} M_{i}^{\beta_{i}}
\end{gathered}
$$

Similarly, in case two moments $\left(M_{i}\right.$ and $M_{j}$ hereafter $)$ are available, dual power law models may be used:

$$
\begin{gathered}
\mathrm{LWC}=C_{i j} M_{i}^{\alpha_{i}} M_{j}^{\alpha_{j}} \\
D_{c}=K_{i j} M_{i}^{\beta_{i}} M_{j}^{\beta_{j}}
\end{gathered}
$$

Introducing (16) and (17) and (18) and (19) into the DSD formulation (14) yields the one- and two-moment DSD scaling formulations, respectively, which are given in Appendix A. More importantly for the purpose of the present study, we use equations (12), (13), and (16)-(19) to express any $k$ th-order moment of the DSD as a single or a dual power law model of the $M_{i}$ and $\left(M_{i}, M_{j}\right)$ moments through the following expressions:

$$
\begin{gathered}
M_{k}=\frac{6}{\rho \pi} \frac{\Gamma(\mu+k+1)}{\Gamma(\mu+4)} C_{i}\left(\frac{K_{i}}{\lambda}\right)^{k-3} M_{i}^{\alpha_{i}+\beta_{i}(k-3)} \\
M_{k}=\frac{6}{\rho \pi} \frac{\Gamma(\mu+k+1)}{\Gamma(\mu+4)} C_{i j}\left(\frac{K_{i j}}{\lambda}\right)^{k-3} M_{i}^{\alpha_{i}+\beta_{i}(k-3)} M_{j}^{\alpha_{j}+\beta_{j}(k-3)}
\end{gathered}
$$

Despite the use of many parameters in the one- and twomoment DSD scaling formulations (6 and 8 parameters, respectively), some self-consistency constraints exist among them. Specifically, for the one-moment DSD formulation (equation (A1)), one obtains two self-consistency constraints by setting $k=i$ in (20), namely,

$$
\alpha_{i}+\beta_{i}(i-3)=1
$$

$$
\frac{6}{\rho \pi} \frac{\Gamma(\mu+i+1)}{\Gamma(\mu+4)} C_{i}\left(\frac{K_{i}}{\lambda}\right)^{i-3}=1
$$

Considering the definition of the characteristic diameter $D_{c}$ (9) and the moment expression (12), a third constraint can be derived as

$$
\mu+4=\lambda
$$

Therefore, there are only three free parameters out of the six in the one-moment DSD formulation.

[10] Similarly, by setting successively $k=i$ and $k=j$ in (21), one obtains the following six self-consistency constraints:

$$
\begin{gathered}
\alpha_{i}=\frac{3-j}{i-j}, \quad \beta_{i}=\frac{1}{i-j}, \quad \alpha_{j}=\frac{3-i}{j-i}, \quad \beta_{j}=\frac{1}{j-i} \\
\frac{6}{\rho \pi} \frac{\Gamma(\mu+i+1)}{\Gamma(\mu+4)} C_{i j}\left(\frac{K_{i j}}{\lambda}\right)^{i-3}=1 \\
\frac{6}{\rho \pi} \frac{\Gamma(\mu+j+1)}{\Gamma(\mu+4)} C_{i j}\left(\frac{K_{i j}}{\lambda}\right)^{j-3}=1
\end{gathered}
$$

Since the constraint (24) also holds in that case, there is actually only one free parameter out of the 8 parameters in the two-moment DSD formulation. Although the scaling law formulation may seem rather complex, it provides a direct link between the classical power laws of radar hydrometeorology and the physics of rain as expressed by the DSD.

\section{Inference of Kinetic Energy Models From DSD Data}

[11] The self-consistency relationships reduce the number of free parameters in the moment estimators (20) and (21). In section 4 , we show the procedures to estimate the climatological values of these parameters by means of a 28 month disdrometer data set.

\subsection{One-Moment Normalization: Parameter Estimation Procedure}

[12] Theoretically, the parameter estimation procedure could be based on the establishment of the power law models (16) and (17). Consideration of LWC instead of $N_{t}$ is likely to significantly improve the relevance of such an approach because of the classical instrumental limitations. However, according to the studies of Sempere Torres et al. [1994] and Hazenberg et al. [2011], a more robust estimation procedure using all DSD moments is proposed, described as follows.

[13] 1. Establish the power law relationships $M_{k}=$ $a_{i k} M_{i}^{b_{i k}}$ between all moments $M_{k}(k=0$ to 6 , with a 0.5 increment) and the explanatory moment $M_{i}(i=3.67$ or $i=6$ ) to derive values of $a_{i k}$ and $b_{i k}$.

[14] 2. Estimate $\alpha_{i}$ and $\beta_{i}$ by the method proposed by Sempere Torres et al. [1994] and Uijlenhoet [2001] on the basis of the linear relationship between the exponent values $b_{i k}(k=0$ to 6$)$ and the order $k$. 
[15] 3. Determine the values of $K_{i}, \lambda$, and $\mu$ from a linear regression analysis of the ratios of consecutive coefficients $a_{i, k+1}$ and $a_{i k}$ derived from the power law relationship (20) under the constraint given by (24),

$$
\theta_{k}=\frac{a_{i, k+1}}{a_{i, k}}=(\mu+1) \frac{K_{i}}{\lambda}+k \frac{K_{i}}{\lambda} .
$$

[16] 4. Calculate the value of $C_{i}$ from the self-consistency relationship (23).

[17] Twenty-eight months of DSD data (except the $14 \mathrm{~h}$ rain event described in section 3 ) are used to estimate the climatic parameters in the one-moment scaled formulation. Figures $3 \mathrm{a}$ and $3 \mathrm{~b}$ display the values of $b_{i k}$ as a function of the moment order $k$ for the scaled formulation based on radar reflectivity factor $(i=6)$ and rain intensity $(i=3.67)$, respectively. In both cases, a good linear relationship is found, except for the low-order moments. This is probably explained by (1) the uncertainty associated with the measurement of small raindrops, which is essential to determine the low-order moments, and (2) the inherent uncertainty in the power law relationships $\left(M_{k}=a_{i k} M_{i}^{b_{i k}}\right)$ between the lowand the high-order moments. Hence, only the third to sixth and second to sixth moments are considered to estimate $\beta$ in the regression analysis for the $Z$ and $R$ scaled formulations, respectively. Next, the values of $\alpha$ derived from the intercepts of the regression are slightly different from those calculated by the self-consistency relationship (22). This phenomenon has also been demonstrated in previous investigations [Sempere Torres et al., 1994; Uijlenhoet et al.,

$a$

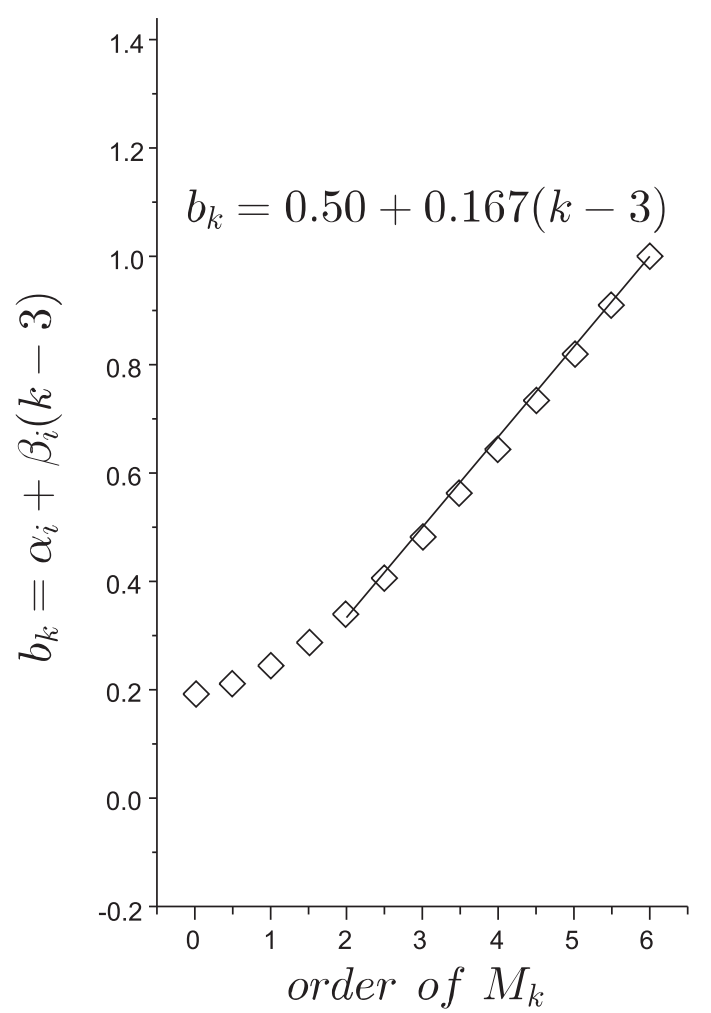

2003]. On the basis of the experience of these authors, the value derived from the self-consistency relationship, rather than the intercept, is retained to estimate $\alpha$.

[18] Figures $4 \mathrm{a}$ and $4 \mathrm{~b}$ show the relationships between the ratios of consecutive coefficients $\left(\theta_{k}=a_{i, k+1} / a_{i, k}\right)$ and the moment order $k$ for the scaled formulation on the basis of rain intensity $(i=3.67)$ and radar reflectivity factor $(i=6)$, respectively. The good linear relationship is used to estimate $K_{i}, \lambda$, and $\mu$ based on the linear expression (28) and the self-consistency constraint (24). Note that, after the estimation of $\alpha_{i}$ and $\beta_{i}$, the exponents $b_{i k}$ in $M_{k}=a_{i k} M_{i}^{b_{i k}}$ are slightly changed. It was found numerically important to adapt the values of the coefficients $a_{i k}$ to coincide with the shift of exponent values $b_{i k}$. For the same reason as mentioned previously, the ratios of low-order moments (e.g., $\left.\theta_{0}=a_{i, 1} / a_{i, 0}\right)$ are not taken into account in the regression analysis. Once $K_{i}, \lambda$ and $\mu$ are determined, $C_{i}$ can finally be derived from the self-consistency relationship (23). All parameters in the one-moment scaled formulation are listed in Table 1. Introducing these climatic values in moment expression (20), one obtains two relationships that link the raindrop kinetic energy flux density $\mathrm{KE}\left(\mathrm{J} \mathrm{m}^{-2} \mathrm{~h}^{-1}\right)$ to the rain intensity $R\left(\mathrm{~mm} \mathrm{~h}^{-1}\right)$ and radar reflectivity factor $Z$ $\left(\mathrm{mm}^{6} \mathrm{~m}^{-3}\right)$,

$$
\begin{aligned}
\mathrm{KE} & =10.16 R^{1.251} \\
\mathrm{KE} & =0.0959 Z^{0.833}
\end{aligned}
$$

Figure 3. Relationship between the exponent $b_{k}$ and the moment order $k$ for (a) $Z$ - and (b) $R$-scaled raindrop size distribution (DSD) formulation. 
$a$

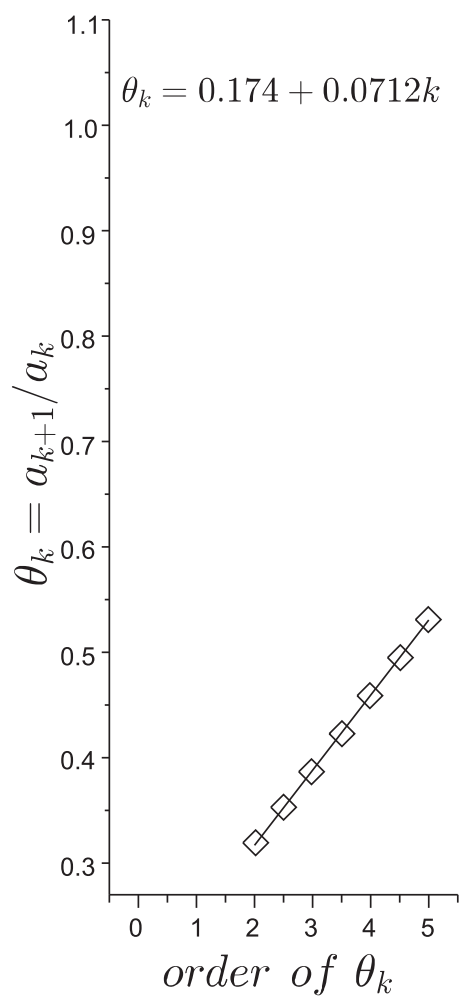

$b$

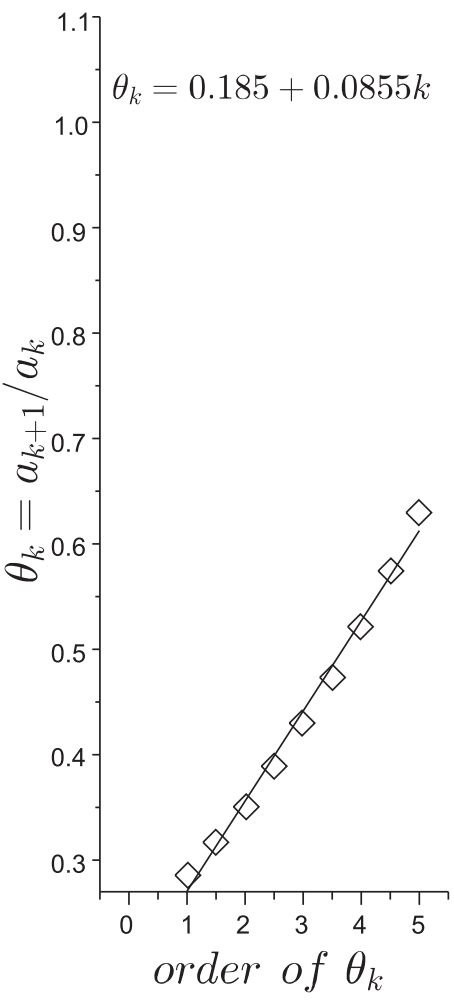

c

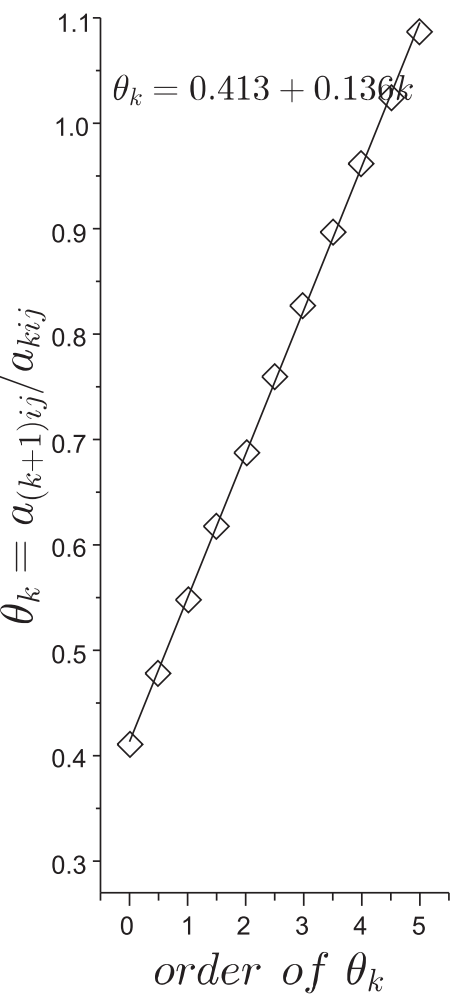

Figure 4. Ratios of consecutive coefficients $\left(\theta_{k}=a_{k+1} / a_{k}\right)$ as a function of the moment order $k$ for (a) $Z$-, (b) $R$-, (c) $R Z$-scaled DSD formulation.

respectively. Figures $5 \mathrm{a}$ and $5 \mathrm{~b}$ display these relationships together with the data points obtained by deriving $\mathrm{KE}, R$ and $Z$ values from each individual DSD spectrum. The KE fitting is evaluated by three criteria (bias, correlation coefficient $(\rho)$, and Nash efficiency coefficient (Nash)) calculated between the measured $\mathrm{KE}_{\mathrm{obs}}$ and the estimated $\mathrm{KE}_{\text {est }}$ through (29) and (30), defined as

$$
\begin{gathered}
\text { Bias }=\frac{\overline{\mathrm{KE}}_{\mathrm{est}}}{\overline{\mathrm{KE}}_{\mathrm{obs}}} \\
\rho=\frac{\sum_{i=1}^{n}\left(\mathrm{KE}_{\mathrm{obs}}^{i}-\overline{\mathrm{KE}}_{\mathrm{obs}}\right)\left(\mathrm{KE}_{\mathrm{est}}^{i}-\overline{\mathrm{KE}}_{\mathrm{est}}\right)}{\sqrt{\sum_{i=1}^{n}\left(\mathrm{KE}_{\mathrm{obs}}^{i}-\overline{\mathrm{KE}}_{\mathrm{obs}}\right)^{2}} \sqrt{\sum_{i=1}^{n}\left(\mathrm{KE}_{\mathrm{est}}^{i}-\overline{\mathrm{KE}}_{\mathrm{est}}\right)^{2}}} \\
\mathrm{Nash}=1-\frac{\sum_{i=1}^{n}\left(\mathrm{KE}_{\mathrm{obs}}^{i}-\mathrm{KE}_{\mathrm{est}}^{i}\right)^{2}}{\sum_{i=1}^{n}\left(\mathrm{KE}_{\mathrm{obs}}^{i}-\overline{\mathrm{KE}}_{\mathrm{obs}}\right)^{2}} .
\end{gathered}
$$

The results are listed in Table 2. A small bias is present for the KE- $R$ relationship, and the KE- $Z$ relationship yields a better estimation of KE. These criteria will be further discussed in section 4.2, together with the performance of the double-moment estimator.

\subsection{Two-Moment Normalization: Parameter Estimation Procedure}

[19] In order to try improving the quality of the estimation, $R$ and $Z$ are applied jointly to estimate $\mathrm{KE}$ on the basis of the two-moment DSD formulation. An interesting feature of the two-moment scaled formulation can be noticed from (25): the exponents of the multiple power law models (18) and (19) only depend on the orders $i$ and $j$ of the considered explanatory moments. Similarly to the one-moment case, considering expression (21) and the self-consistency relationships (24)- (27), we propose the following estimation procedure for the two-moment DSD formulation:

[20] 1. Establish the multiple power law relationships $M_{k}=a_{i j k} M_{i}^{b_{k i}} M_{j}^{b_{k j}}$, based on (21), between all moments $M_{k}$ ( $k=0$ to 6$)$ and the observed moments $M_{i}, M_{j}(i=3.67$,

Table 1. Comparison of Estimated Parameters in Different DSD Scaling Formulations ${ }^{a}$

\begin{tabular}{lccccccccc}
\hline$M_{\boldsymbol{i}}$ & $C$ & $\alpha_{i}$ & $\alpha_{j}$ & $K$ & $\beta_{i}$ & $\beta_{j}$ & $\mu$ & $\lambda$ & $C^{a}$ \\
\hline$Z$ & 5534 & 0.500 & & 0.388 & 0.170 & & 1.448 & 5.448 & \\
$R$ & 448,570 & 0.874 & & 0.442 & 0.189 & & 1.163 & 5.163 & \\
$R Z$ & 61.873 & 1.288 & -0.288 & 0.823 & -0.429 & 0.429 & 2.028 & 6.028 & 62.081 \\
\hline
\end{tabular}

${ }^{\text {a }}$ For the $R Z$ scaling raindrop size distribution (DSD) formulation, $C$ can be estimated in two ways (equation (26) or (27)), indicated separately as $C$ and $C^{a}$ here. See section 3.3 for more details. 
$a$

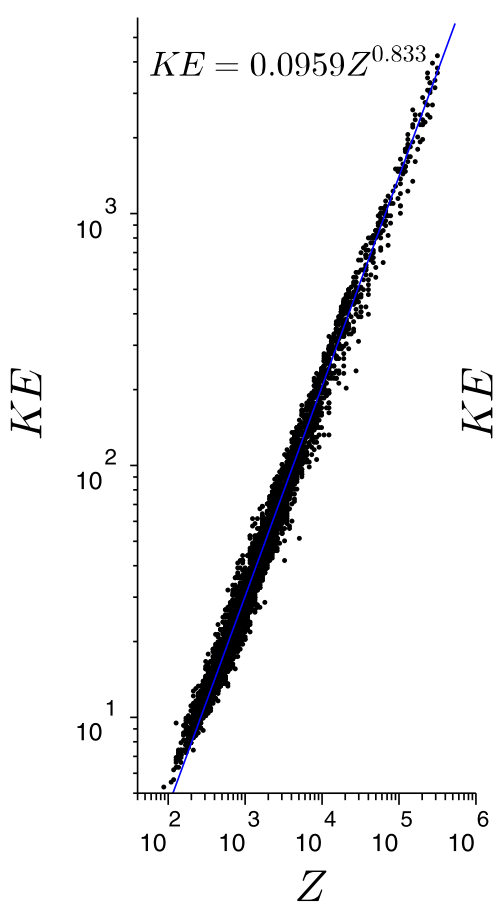

$b$

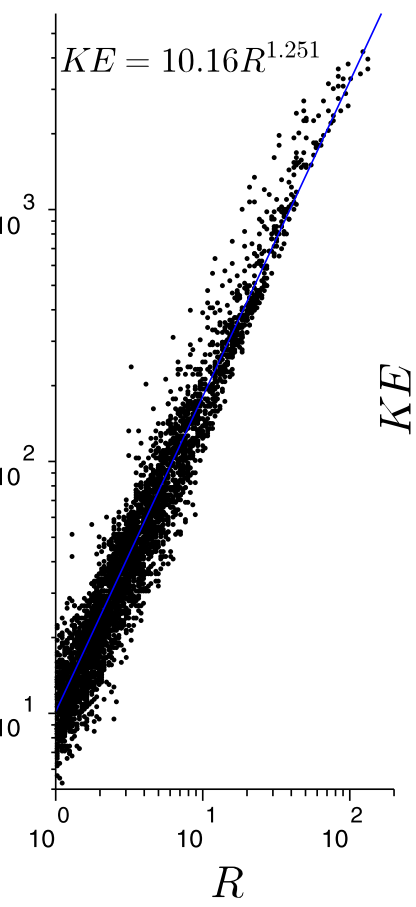

$c$

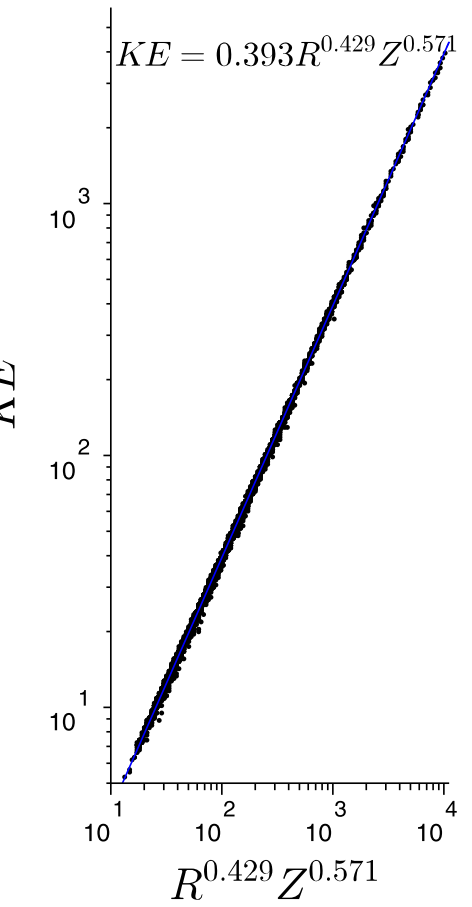

Figure 5. Rain kinetic energy flux density KE as a function of observed moments and their combination, with $\mathrm{KE}$ in $\mathrm{J} \mathrm{m}^{-2} \mathrm{~h}^{-1}, Z$ in $\mathrm{mm}^{6} \mathrm{~m}^{-3}$ and $R$ in $\mathrm{mm} \mathrm{h}^{-1}$.

$j=6$ ) by forcing the exponent $b_{k i}$ and $b_{k j}$ equal to appropriate values through (25).

[21] 2. With the self-consistency relationship (24) and the moment expression (21), determine the values of $K_{i j}, \lambda$ and $\mu$ from a linear regression analysis of the ratio of consecutive coefficients $a_{i j,(k+1)}$ and $a_{i j, k}$, as a function of $k$

$$
\theta_{k}=\frac{a_{i j,(k+1)}}{a_{i j, k}}=(\mu+1) \frac{K_{i j}}{\lambda}+k \frac{K_{i j}}{\lambda}
$$

[22] 3. Calculate the final parameter $C_{i j}$ either from the self-consistency relationship (26) or from (27). This step allows us to verify our theory by comparing $C_{i j}$ values derived by different self-consistency relationships.

[23] Figure $4 \mathrm{c}$ illustrates the ratio of consecutive coefficients $\theta_{k}$ as a function of the moment order $k$, derived from the coefficient $a_{i j, k}$ in the multiple power law relationships $M_{k}=a_{i j, k} R^{(6-k) / 2.33} Z^{(k-3.67) / 2.33}$. The parameters $\left(K_{i j}, \lambda\right.$, and $\mu$ ) are estimated from the slope and intercept of the

Table 2. Performance of Different Models to Estimate KE on the Basis of the 28 Month Disdrometer Data, Which Are Used to Calibrate the KE Models ${ }^{\mathrm{a}}$

\begin{tabular}{lccc}
\hline KE Estimator & Bias & $\rho$ & Nash \\
\hline$Z_{D S D}-\mathrm{KE}_{\mathrm{DSD}}$ & 1.001 & 0.989 & 0.977 \\
$R_{D S D}-\mathrm{KE}_{\mathrm{DSD}}$ & 0.954 & 0.964 & 0.924 \\
$R Z_{D S D}-\mathrm{KE}_{\mathrm{DSD}}$ & 1.010 & 1.000 & 1.000 \\
\hline
\end{tabular}

${ }^{\mathrm{a}} \mathrm{KE}$, rainfall kinetic energy. straight solid line with the self consistency relationship (24). In parallel with the one-moment DSD scaling formulation, we show the parameter values of the $R Z$-scaled DSD formulation in Table 1 . Note that the two estimates of $C_{i j}$ derived from (26) and (27) are very similar. A climatological estimator of the raindrop kinetic energy flux density, based on moment expression (21), is derived as

$$
\mathrm{KE}=0.393 R^{0.429} Z^{0.571}
$$

Figure $5 \mathrm{c}$ displays the relationship between $\mathrm{KE}$ and $R^{(6-5) / 2.33} Z^{(5-3.67) / 2.33}$. One can immediately note the improvement in the estimation of $\mathrm{KE}$ when $R$ and $Z$ are used jointly. Three relationships (29), (30), and (35), derived from the DSD scaling formulation, are represented by the solid lines in Figure 5, agreeing well with the observations. We evaluate the KE- $R Z$ relationship by the three criteria (31)-(33) and list the results in Table 2. Generally, the three criteria exhibit the same trend. Naturally, the twomoment relationship KE- $R Z$ yields the best estimation of kinetic energy flux density. Concerning single-moment estimation, the radar reflectivity factor $Z$ provides a better estimation than the rain intensity $R$. This is mainly because the kinetic energy flux density is nearly proportional to the fifth-order moment, which is closer to the radar reflectivity (sixth-order moment). The near perfect quality of the estimation from $R$ and $Z$ jointly shows the potential advantage of combining two moments that are widely accessible in hydrometeorological observation networks with radars and rain gauges. However, one may note that the DSD evaluation data are the same as those used in the fitting procedure. 
In order to justify the arguments, new independent data are considered to assess the KE estimators in section 4.3.

\subsection{Assessment of the Three Estimators Based on Independent Disdrometer Data}

[24] A $14 \mathrm{~h}$ rain event is used to assess the KE estimators (29), (30), and (35). Approximately three rain phases can be distinguished during this event (Figure 2b). The first phase, which lasts for about $2 \mathrm{~h}$, consists of moderate rainfall $\left(10 \mathrm{~mm} \mathrm{~h}^{-1}\right)$. Then, an intense rain shower follows with a maximum rain rate of $R=60 \mathrm{~mm} \mathrm{~h}^{-1}$. Next, light rain continues from dawn to the end of the rain event. The KEs derived from the DSD are compared to those estimated from the three relationships (29), (30) and (35). We recall that the $Z$ and $R$ are also derived from the DSD. The same criteria (bias, correlation coefficient $\left(\rho^{2}\right)$, and Nash efficiency coefficient (Nash)) are used in the evaluation and the results are shown in Table 3. Similarly, the twomoment relationship KE- $R Z$ always yields the best estimation of KE, while both single-moment relationships yield an underestimation. This bias is probably due to the presence of the intense convective systems in the event. Therefore, the climatological relationships (29) and (30) are not appropriate to this rainfall system. Comparison of the performances in Table 3 supports the advantages of the KE- $R Z$ relationship in $\mathrm{KE}$ estimation regardless of the type of rainfall.

\section{Toward the Spatialization of Rainfall Kinetic Energy Flux Density}

[25] We have considered in section 4 one of the most intense events out of the 28 month time series which occurred on 22 October 2008. However, only the disdrometer data at one point has been considered so far. Hereafter, (1) we illustrate the potential of weather radar to deliver high-resolution KE maps thanks to the radar reflectivity fields, (2) then we compare the statistical distributions of the $\mathrm{KE}$ values derived from the three climatological relationships (29), (30), and (35) using weather radar data $(Z)$ and/or the rain rates $(R)$ provided by the $5 \mathrm{~min}$ rain gauge network, and (3) finally, we assess the KE values, at one point, derived from the radar and/or rain gauge data sets, by using the available disdrometer data in Alès.

\subsection{Spatialization of the Rainfall Kinetic Energy Flux Density}

[26] A direct conversion of the 5 min radar reflectivities available for the 22 October 2008 rain event using (30) yields high-resolution images $\left(1 \mathrm{~km}^{2}, 5 \mathrm{~min}\right)$ of $\mathrm{KE}$ values such as those displayed in Figure 6 during the most intense part of this rain event. The large spatial and temporal variability of the kinetic energy are particularly remarkable for this event. Used in conjunction with GIS layers concerning

Table 3. Performance of Different Models to Estimate KE on the Basis of the Rain Event of 22 October $2008^{\mathrm{a}}$

\begin{tabular}{lccc}
\hline KE Estimator & Bias & $\rho$ & Nash \\
\hline$Z_{D S D}-\mathrm{KE}_{\mathrm{DSD}}$ & 0.958 & 0.997 & 0.992 \\
$R_{D S D}-\mathrm{KE}_{\mathrm{DSD}}$ & 0.897 & 0.995 & 0.980 \\
$R Z_{D S D}-\mathrm{KE}_{\mathrm{DSD}}$ & 0.992 & 1.000 & 1.000 \\
\hline
\end{tabular}

${ }^{\mathrm{a}}$ The disdrometer data are not included in the calibration data set. topography, soil properties and land use, we believe such $\mathrm{KE}$ images to have a strong potential for a better understanding of erosion processes.

[27] As part of the available rain gauge network supported by the French Flood Forecasting Service SPC-GD, we were able to collect $5 \mathrm{~min}$ rain rate time series for the 12 rain gauges indicated in Figure 6 . Note that the KE value derived from each $5 \mathrm{~min}$ rain rate value using (29) is used to define the color of the rain gauge pictogram in accordance with the KE scale. The four selected images in Figure 6 show a good overall agreement between the radarand rain gauge-derived $\mathrm{KE}$ values, with some exceptions that may be due, among many other reasons, to timing problems and sampling issues for such fine scale comparisons. This is why we are comparing the radar-, rain gauge-, and radar plus rain gauge-KE estimates in terms of cumulative distribution functions (CDF) in Figure 7. The differences are significant, e.g., for KE values less than 1000 $\mathrm{J} \mathrm{m}^{-2} \mathrm{~h}^{-1}$, the cumulative frequencies are equal to 0.925 , 0.955 , and 0.970 for the rain gauge-, radar + rain gauge-, and radar-KE estimates, respectively. Figure 7 indicates that the rain gauge network produces significantly higher $\mathrm{KE}$ values compared to the radar, and the combination of the two sources of data gives intermediate KE estimations. The KE values estimated by the rain gauge network are not consistent with the previous results listed in Table 2 and Table 3, for which the rain rate always yields an underestimation of KE compared to the radar reflectivity factor. To get an in-depth understanding of the reasons for such CDF differences, we consider the disdrometer data at Alès, as the reference of KE measurement, to evaluate the relationships (29), (30), and (35) in section 5.2. To conclude about the KE spatialization, we simply mention that refined estimation techniques, such as cokriging, could be considered for efficiently merging the available radar and rain gauge data into KE fields with the desired high space-time resolution. This topic will be the subject of future work.

\subsection{Assessment of the Radar and/or Rain Gauge KE Estimators With the Disdrometer Data for the 22 October 2008 Rain Event}

[28] The differences of the $3 \mathrm{KE} \mathrm{CDFs}$ derived from radar, rain gauge and radar + rain gauge are most likely explained by (1) an underestimation of the radar reflectivities related to a calibration problem and/or sampling issues (point versus volume measurements) and/or (2) the nonappropriateness of the climatological relationships for the considered convective rain event, while the 28 month period includes a vast range of precipitating systems. Figure 8 displays the time series of the KE derived directly from the disdrometer spectra and through relationships (29), (30) and (35) using the corresponding observations (rain gauge and radar data). Results of the statistical comparison are listed in Table 4. In addition, the comparisons of the rain rate provided by disdrometer and rain gauge, as well as the reflectivity factor provided by disdrometer and radar, are also demonstrated. These results confirm the overall consistency of the KE estimations and their good cofluctuation with the direct observations provided by disdrometer. Similar to the CDFs presented in Figure 7, the radar also yields an underestimation of $\mathrm{KE}(0.878)$, compared to that estimated by the rain gauge $(0.983)$. One should note the 

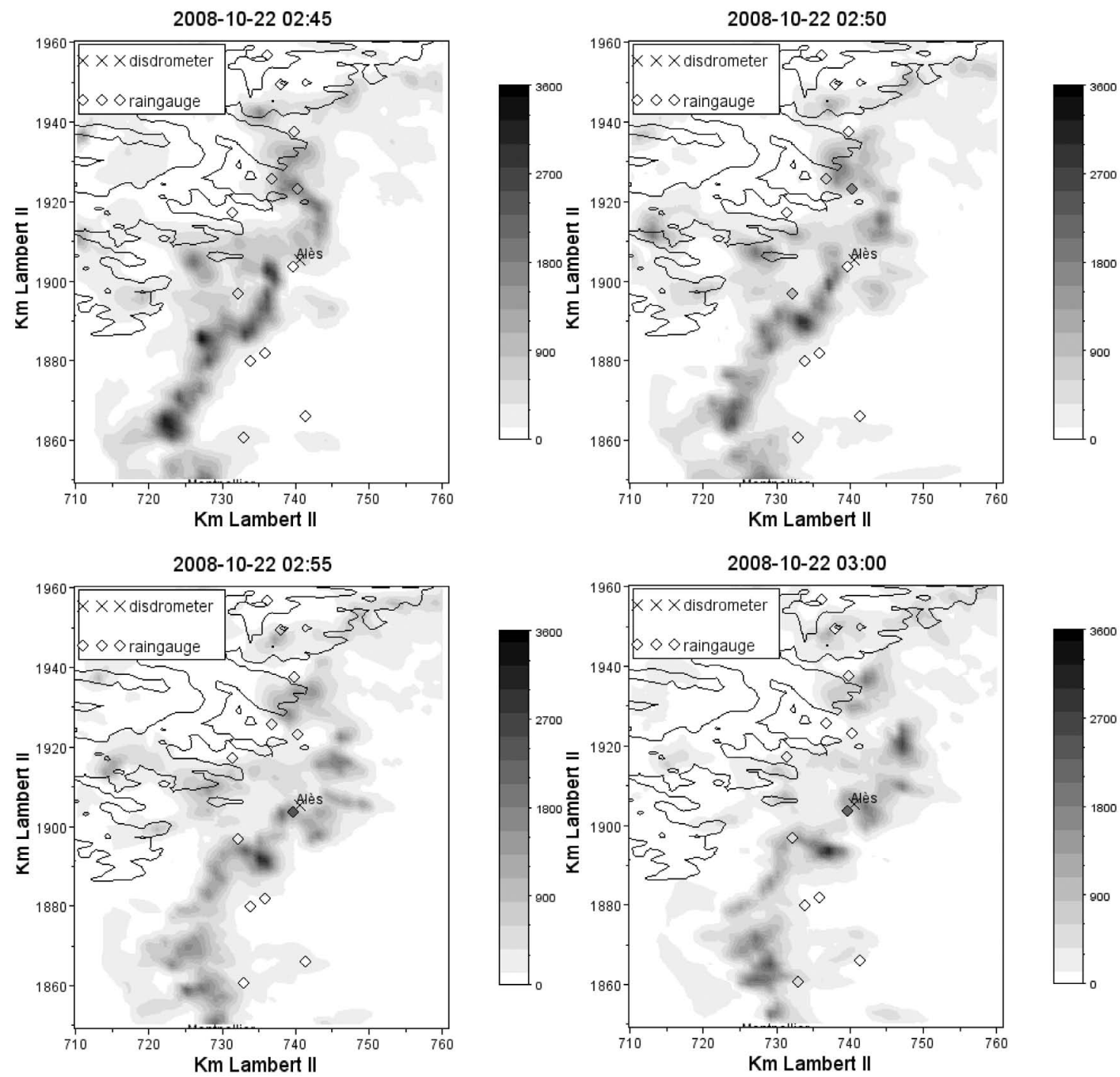

Figure 6. Maps of the kinetic energy flux density $\mathrm{KE}\left(\mathrm{J} \mathrm{m}^{-2} \mathrm{~h}^{-1}\right)$ derived from $Z$ in the region of Alès, at 02:45 UTC, 02:50 UTC, 02:55 UTC, and 03:00 UTC on 22 October 2008. The rain gauge pictograms are colored as a function of the $\mathrm{KE}$ values derived from the observed rain rate.

negative bias (0.902) in the comparison of $Z$ provided by the radar and by the disdrometer. It seems that the bias of the radar reflectivities with respect to the disdrometer reflectivities is amplified by the nonlinear KE- $Z$ relationship and the sampling problem, while a slightly better agreement is obtained for the KE- $R$ relationships. The improved performance of the KE- $R$ relationships may be explained by the proximity and the sampling characteristics of the disdrometer and the rain gauge, while the reflectivity measurements come from two very different sensors and resolution volumes. In this case study again, the KE- $R Z$ relationship yields the better performance evaluated by the $\rho$ and the Nash criteria.

\section{Conclusion}

[29] This study presents three models to estimate the rainfall kinetic energy flux density KE from rain intensity $(R)$ and/or from radar reflectivity factor $(Z)$. The estimated models are originally based on a scaling DSD formulation, containing the liquid water content (LWC), the characteristic diameter $\left(D_{c}\right)$ and a two-parameter gamma probability density function (pdf) of scaled drop diameters. Next, by introducing single and multiple power law models between the observations (e.g., $R$ and/or $Z$ ) and the variables (LWC and $D_{c}$ ), we derive the one- and two-moment scaled DSD formulations. Taking into account the self-consistency relationships, a robust procedure is proposed to estimate the parameters in these formulations. This procedure utilizes appropriate DSD moments in the estimation to overcome the measurement uncertainty of small drops. Three KE models (KE- $R$, KE- $Z$, and KE- $R Z$ ) are established on the basis of the one- or two-moment DSD scaling formulation with the estimated parameters. Evaluations of these models both on the DSD-derived moments and on a radar-rain gauge data set indicate that the combination of two observations ( $R$ and $Z$ ) improves the quality of estimating $\mathrm{KE}$ significantly. In the case of one-moment estimation, as $Z$ is 


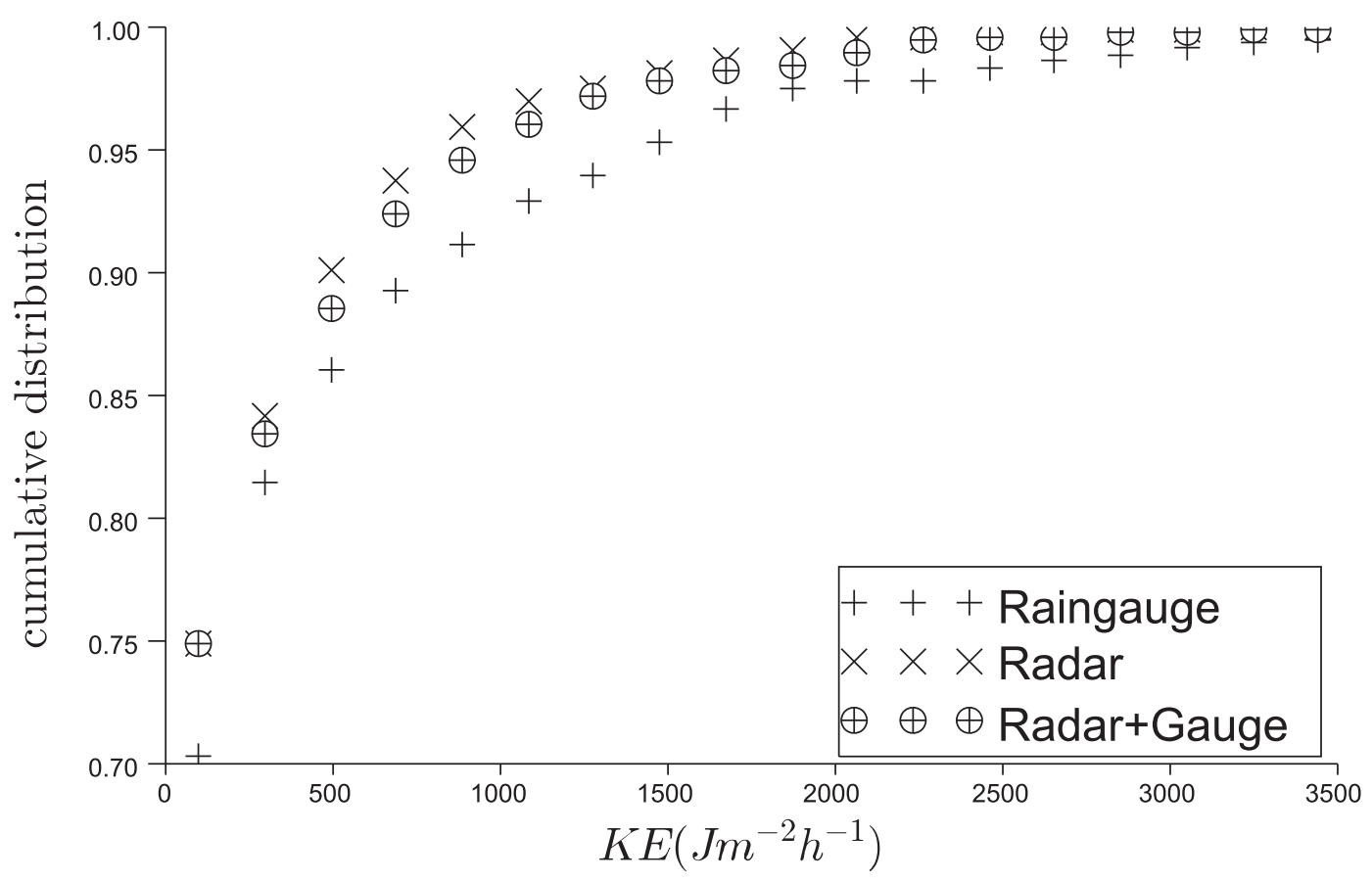

Figure 7. Cumulative distribution function of $\mathrm{KE}$ derived from the three estimators for 12 rain gauge stations during the 22 October 2008 rain event.

$a$
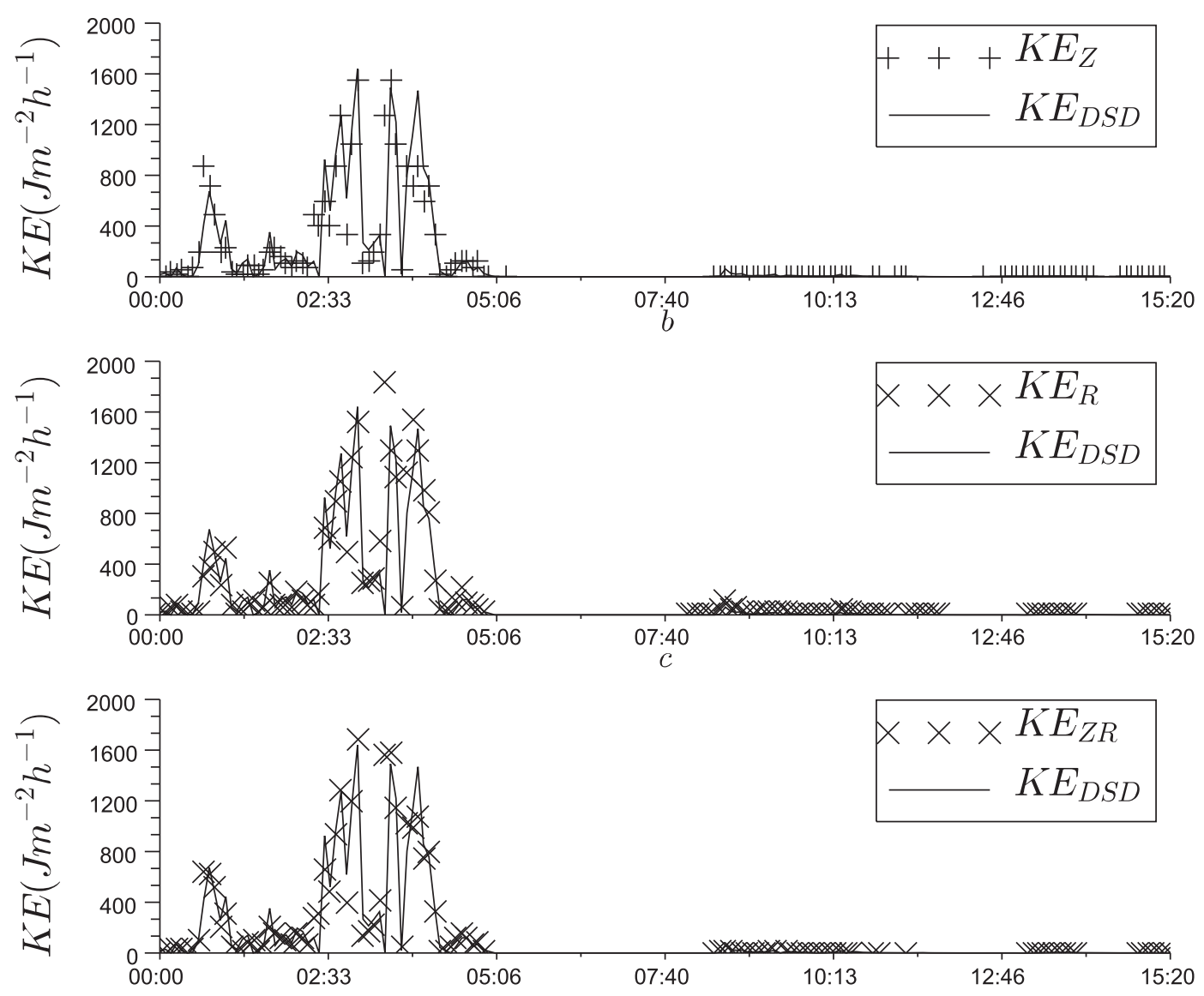

Figure 8. Comparison of time series of KE derived for the 22 October 2008 rain event from the disdrometer and (a) from the radar reflectivity factor $Z$, (b) from the rain rate $R$, and (c) from the $R$ and $Z$ jointly. 
Table 4. Performance of Different Models to Estimate KE, With the Comparison of Observations Based on the Weather Radar, Rain Gauge, and DSD Data Set

\begin{tabular}{lccc}
\hline \multicolumn{1}{c}{ KE Estimator } & Bias & $\rho$ & Nash \\
\hline$Z_{\text {radar }}-\mathrm{KE}_{\mathrm{DSD}}$ & 0.878 & 0.953 & 0.901 \\
$R_{\text {gauge }}-\mathrm{KE}_{\mathrm{DSD}}$ & 0.983 & 0.972 & 0.944 \\
$R_{\text {gauge }} Z_{\text {radar }}-\mathrm{KE}_{\mathrm{DSD}}$ & 0.938 & 0.981 & 0.961 \\
$Z_{\text {radar }}-Z_{D S D}$ & 0.902 & 0.952 & 0.903 \\
$R_{\text {gauge }}-R_{D S D}$ & 1.020 & 0.982 & 0.956 \\
\hline
\end{tabular}

an approximate moment to $\mathrm{KE}, Z$ theoretically yields a better estimation than the KE- $R$ relationship. However, for the considered radar-rain gauge data set, because of radar sampling problems and the fact that the rain gauge is collocated with the disdrometer, the performance of KE- $R$ relationship is better than the KE- $Z$ relationship. The performance of the estimation can be improved when $R$ is used jointly with $Z$ in the estimation. Our study reveals the advantage of combining two observations to estimate a third DSD moment. Similarly, one can expect that the reconstitution of the DSD by two observations $(Z$ and $R$ ) will be more robust compared to the method based on one observation $(Z$ or $R)$. Thus it will be interesting to investigate the spatial and temporal characteristics of the DSD reconstituted by two observations in the future. Another important issue is to investigate the sensitivity of the KE relationships on the raindrop terminal velocity model. Precise instruments (e.g., 2DVD) will be used in forthcoming experiments to assess this point.

\section{Appendix A: Expressions of the DSD in the One- and Two-Moment Normalization Framework}

\section{A1. One-Moment Normalization}

[30] Introducing the power-law models (16) and (17) into the scaling DSD formulation (14) yields

$$
N(D)=\left[K_{11} M_{i}^{\alpha_{i}-4 \beta_{i}}\right] K_{12}\left(\frac{D}{M_{i}^{\beta_{i}}}\right)^{\mu} \exp \left(-\frac{K_{13} D}{M_{i}^{\beta_{i}}}\right)
$$

where $\left(K_{11}, K_{12}, K_{13}\right)$ are numerical constants depending on the $(\lambda, \mu)$ parameters and the parameters of the single power law models (16) and (17):

$$
K_{11}=C_{L W C} \frac{C_{i}}{K_{i}^{4}} ; \quad K_{12}=\frac{\lambda^{\mu+1}}{K_{i}^{\mu} \Gamma(\mu+1)} ; \quad K_{13}=\frac{\lambda}{K_{i}} .
$$

\section{A2. Two-Moment Normalization}

[31] Introducing the dual power-law models (18) and (19) into the scaling DSD formulation (14) yields

$$
N(D)=\left[K_{21} M_{i}^{\alpha_{i}-4 \beta_{i}} M_{j}^{\alpha_{j}-4 \beta_{j}}\right] K_{22}\left(\frac{D}{M_{i}^{\beta_{i}} M_{j}^{\beta_{j}}}\right)^{\mu} \exp \left(-\frac{K_{23} D}{M_{i}^{\beta_{i}} M_{j}^{\beta_{j}}}\right)
$$

where $\left(K_{21}, K_{22}, K_{23}\right)$ are numerical constants which depend on the $(\lambda, \mu)$ parameters and the parameters of the double power law models (18) and (19):

$$
K_{21}=C_{L W C} \frac{C_{i j}}{K_{i j}^{4}} ; \quad K_{22}=\frac{\lambda^{\mu+1}}{K_{i j}^{\mu} \Gamma(\mu+1)} ; \quad K_{23}=\frac{\lambda}{K_{i j}} .
$$

[32] Acknowledgments. The contribution of Remko Uijlenhoet to this study was supported financially by the EU-FP7 Project IMPRINTS (FP7ENV-2008-1-226555). All authors would also like to thank the HYDRATE project of the European Community (GOCE 037024) for financial support. The authors especially thank Pierre-Alain Ayral (École des Mines d'Alès) and the technical support of LTHE for the maintenance of DSD measurements and the anonymous reviewers for their valuable comments.

\section{References}

Anquetin, S., F. Miniscloux, J. D. Creutin, and S. Cosma (2003), Numerical simulation of orographic rainbands, J. Geophys. Res., 108(D8), 8386, doi:10.1029/2002JD001593.

Assouline, S., and Y. Mualem (1989), The similarity of regional rainfall: A dimensionless model of drop size distribution, Trans. ASAE, 32(4), 1216-1222.

Atlas, D., and C. W. Ulbrich (1977), Path- and area-integrated rainfall measurement by microwave attenuation in the $1-3 \mathrm{~cm}$ band, J. Appl. Meteorol., 16, 1322-1331.

Beard, K. V. (1976), Terminal velocity and shape of cloud and precipitation drops aloft, J. Atmos. Sci., 23, 851-864.

Best, A. (1950), The size distribution of raindrops, Q. J. R. Meteorol. Soc., 76, 16-36.

Boudevillain, B., G. Delrieu, B. Galabertier, L. Bonnifait, L. Bouilloud, P. E. Kirstetter, and M. L. Mosini (2011), The Cévennes-Vivarais Mediterranean hydrometeorological observatory database, Water Resour. Res., 47, W07701, doi:10.1029/2010WR010353.

Delrieu, G., et al. (2005), The catastrophic flash-flood event of 8-9 September 2002 in the Gard region, France: A first case study for the CévennesVivarais Mediterranean Hydrometeorological Observatory, J. Hydrometeorol., 6(1), 34-52.

Erpul, G., L. D. Norton, and D. Gabriels (2003), The effect of wind on raindrop impact and rainsplash detachment, Trans. ASAE, 46, 51-62.

Fornis, R. L., H. R. Vermeulen, and J. D. Nieuwenhuis (2005), Kinetic energy-rainfall intensity relationship for central Cebu, Philippines for soil erosion studies, J. Hydrol., 300, 20-32.

Fox, I. N. (2004), The representation of rainfall drop-size distribution and kinetic energy, Hydrol. Earth Syst. Sci., 8(5), 1001-1007.

Gossard, E. E., R. G. Strauch, D. C. Welsh, and S. Y. Matrosov (1992), Cloud layers, particle identification, and rain-rate profiles from ZRVf measurements by clear-air Doppler radars, J. Atmos. Oceanic Technol., 9(2), 108-119.

Gunn, R., and G. Kinzer (1949), The terminal velocity of fall for water droplets in stagnant air, J. Appl. Meteorol., 6, 243-248.

Hazenberg, P., N. Yu, B. Boudevillain, G. Delrieu, and R. Uijlenhoet (2011), Scaling of raindrop size distributions and classification of radar reflectivity-rain rate relations in intense Mediterranean precipitation, J. Hydrol., 402, 179-192.

Illingworth, A. J., and T. M. Blackman (2002), The need to represent raindrop size spectra as normalized gamma distributions for the interpretation of polarization radar observations, J. Appl. Meteorol., 41(3), 286-297.

Intergovernmental Panel on Climate Change (2007), Contribution of Working Group II to the Fourth Assessment Report of the Intergovernmental Panel on Climate Change, edited by M. L. Parry et al., 976 pp., Cambridge Univ. Press, Cambridge, U. K.

Jaffrain, J., and A. Berne (2011), Experimental quantification of the sampling uncertainty associated with measurements from PARSIVEL disdrometers, J. Hydrometeorol., 12(3), 352-370

Kinnell, P. I. A. (1973), The problem of assessing the erosive power of rainfall from meteorological observations, Soil Sci. Soc. Am. Proc., 37, 617-621

Laflen, J. M., W. J. Elliot, D. C. Flanagan, C. R. Meyer, and M. A. Nearing (1997), WEPP predicting water erosion using a process-based model, J. Soil Water Conserv., 52(2), 96-102. 
Lee, G. W., I. Zawadzki, W. Szyrmer, D. Sempere Torres, and R. Uijlenhoet (2004), A general approach to double-moment normalization of drop size distributions, J. Appl. Meteorol., 43(2), 264-281.

Mihara, Y. (1951), Raindrops and soil erosion, Bull. Natl. Inst. Agric. Sci., Ser. A, 1, 48-51.

Morgan, R. P. C., J. N. Quinton, R. E. Smith, G. Govers, J. W. A. Poesen, K. Auerswald, G. Chisci, D. Torri, and M. E. Styczen (1998), The European Soil Erosion Model (EUROSEM): A dynamic approach for predicting sediment transport from fields and small catchments, Earth Surf. Processes Landforms, 23, 527-544.

Mualem, Y., and S. Assouline (1986), Mathematical model for rain drop distribution and rainfall kinetic energy, Trans. ASAE, 29(2), 494-500.

Nuissier, O., V. Ducrocq, D. Ricard, C. Lebeaupin, and S. Anquetin (2008), A numerical study of three catastrophic precipitating events over southern France. I: Numerical framework and synoptic ingredients, $Q . J . R$. Meteorol. Soc., 134, 111-130.

Porrá, J. M., D. Sempere Torres, and J. D. Creutin (1998), Modeling of drop size distribution and its applications to rainfall measurements from radar, in Stochastic Methods in Hydrology, Adv. Ser. Stat. Sci. Appl. Probab., vol. 7, edited by O. E. Bandorff-Nielsen et al., pp. 73-84, World Sci., Singapore.

Salles, C., and J. D. Creutin (2003), Instrumental uncertainties in Z-R relationships and raindrop fall velocities, J. Hydrol., 42, 279-290.

Salles, C., J. Poesen, and D. Sempere Torres (2002), Kinetic energy of rain and its functional relationship with intensity, J. Hydrol., 257, 256-270.

Sempere Torres, D., C. Salles, J. D. Creutin, and G. Delrieu (1992), Quantification of soil detachment by raindrop impact: Performance of classical formulae of kinetic energy in Mediterranean storms, in Erosion and Sediment Transport Monitoring Programs in River Basins, 210, 115-124, IASH Publ., Oxfordshire, U. K.

Sempere Torres, D., J. M. Porrà, and J. D. Creutin (1994), A general formulation for raindrop size distribution, J. Appl. Meteor., 33(12), 1494-1502.
Sempere Torres, D., J. M. Porrà, and J. D. Creutin (1998), Experimental evidence of a general description for raindrop size distribution properties, J. Geophys. Res., 103, 1785-1797.

Steiner, M., and J. A. Smith (2000), Reflectivity, rain rate, and kinetic energy flux relationships based on raindrop spectra, J. Appl. Meteorol., 39(11), 1923-1940.

Testud, J., S. Oury, R. A. Black, P. Amayenc, and X. K. Dou (2001), The concept of 'normalized' distribution to describe raindrop spectra: A tool for cloud physics and cloud remote sensing, J. Appl. Meteorol., 40(6), 1118-1140.

Tokay, A., R. Wolff, P. Bashor, and O. Dursun (2003), On the measurement errors of the Joss-Waldvogel disdrometer, paper presented at 31st Conference on Radar Meteorology, Am. Meteorol. Soc., Seattle, Wash.

Uijlenhoet, R. (2001), Raindrop size distributions and radar reflectivityrain rate relationships for radar hydrology, Hydrol. Earth Syst. Sci., 5(4), 615-627.

Uijlenhoet, R., and J. N. M. Stricker (1999), A consistent rainfall parameterization based on the exponential raindrop size distribution, J. Hydrol., 218(1999), 101-127.

Uijlenhoet, R., J. A. Smith, and M. Steiner (2003), The microphysical structure of extreme precipitation as inferred from ground-based raindrop spectra, J. Atmos. Sci., 60(10), 1220-1238.

Ulbrich, C. W. (1983), Natural variations in the analytical form of the raindrop size distribution, J. Appl. Meteorol., 22(10), 1764-1775.

Van Dijk, A. I. J. M., A. G. C. A. Meesters, J. Schellekens, and L. A. Bruijnzeel (2005), A two-parameter exponential rainfall depth-intensity distribution applied to runoff and erosion modelling, J. Hydrol., 300, 155-171.

B. Boudevillain, G. Delrieu, and N. Yu, LTHE, UMR 5564, UJFGrenoble 1/CNRS/G-INP/IRD, Bâtiment OSUG-B, Domaine Universitaire, BP 53, F-38041 Grenoble Cedex 9, France. (yunansh@hotmail.com) R. Uijlenhoet, Hydrology and Quantitative Water Management Group, Wageningen University, PO Box 47, NL-6700 AA Wageningen, Netherlands. 